\title{
The Effects of Whole Body Vibration Treatments on Lower Body Muscular Activity in Well-Trained Athletes from Different Sports Branches
}

\author{
İlbilge Özsu ${ }^{1}$, Hayri Ertan ${ }^{2}$, Deniz Şimşek ${ }^{2}$, Bahtiyar Özçaldiran ${ }^{3}$, Cem Kurt $^{4}$ \\ ${ }^{1}$ Uşak University, Faculty of Sports Sciences, Uşak, Turkey \\ ${ }^{2}$ Anadolu University, Faculty of Sports Sciences, Eskişehir, Turkey \\ ${ }^{3}$ Ege University, Faculty of Sports Sciences, İzmir, Turkey \\ ${ }^{4}$ Trakya University, School of Physical Education and Sports, Edirne, Turkey \\ Correspondence: İlbilge Özsu, Faculty of Sports Sciences, Uşak University, Uşak, TR 64000, Turkey.
}

Received: July 10, $2018 \quad$ Accepted: July 31, $2018 \quad$ Online Published: August 3, 2018

doi:10.11114/jets.v6i9a.3512 URL: https://doi.org/10.11114/jets.v6i9a.3512

\begin{abstract}
A limited number of acute whole body vibration (WBV) studies have investigated the effects of WBV treatments which were applied with different vibration frequencies and amplitude combinations on lower extremity muscle activation of well-trained athletes from different sports branches. To compare the effects of WBV on lower extremity muscle activation via Surface Electromyography (sEMG) of well-trained athletes from different sports branches (soccer, basketball and swimming) during static and dynamic squat exercises. sEMG activities of Tibialis Anterior (TA), Gastrocnemius Medialis (GM), Vastus Medialis (VM), Rectus Femoris (RF), Vastus Lateralis (VL) and Biceps Femoris (BF) muscles of 7 male soccer players, 7 male basketball players, and 6 male swimmers were recorded during WBV applied in static squat and dynamic squat positions with different frequencies $(30-35-40 \mathrm{~Hz})$ and amplitude $(2-4 \mathrm{~mm})$ combinations separated from each other by 5 min passive rest periods. Each combination was applied for $30 \mathrm{sec}$. The highest muscle activation was determined in TA of the swimmers compared to soccer players during static squat with $4 \mathrm{~mm}-30 \mathrm{~Hz}$ WBV application ( $\mathrm{p}=0.027$ ). The lowest muscle activation was also determined in VL of the swimmers compared to soccer players during static squat with $2 \mathrm{~mm}-40 \mathrm{~Hz}$ WBV $(\mathrm{p}=0.049)$. During dynamic squat with $4 \mathrm{~mm}-40 \mathrm{~Hz} \mathrm{WBV}$, the highest muscle activity was determined in RF of the basketball players compared to swimmers $(\mathrm{p}=0.030)$. However, dynamic squat with $2 \mathrm{~mm}-40 \mathrm{~Hz} \mathrm{WBV}$ application gave rise to the lowest muscle activation in VL of the basketball players compared to soccer players $(\mathrm{p}=0.042)$. Well-trained athletes from different sports branches demonstrated different neuromuscular responses to acute WBV treatments. WBV during dynamic squatting which was applied with $4 \mathrm{~mm}-40 \mathrm{~Hz}$ may be more beneficial in enhancing neuromuscular performance acutely for well-trained male athletes since it resulted in higher levels of muscular activation responses according to the present study.
\end{abstract}

Keywords: vertical vibration, squat position, electromyography, soccer player, basketball player, swimmer

\section{Introduction}

Strength development is the vital factor not only for performance enhancement of athletes, but also for the prevention of sports injuries. Athletes and coaches have performed strength training by using traditional methods including free weights, machines, plyometric drills, and isokinetic devices. However, new training methods or techniques which require less time and are easier to perform have supplanted these traditional methods (Fernandez-Rio et al., 2010). For the last decade, it has been reported that one of the most popular new training methods is vibration stimulation which is a mechanical stimulus characterized by an oscillatory motion.

In literature, there are a lot of investigations about the beneficial effects of vibration on muscular performance through a neural adaptation (Bosco et al., 1998; Delecluse et al., 2003; Verschueren et al., 2004a; Roelants et al., 2004; Torvinen et al., 2002; Torvinen et al., 2003; Verschueren et al., 2004b). However, there is no consensus about the mechanism of the vibratory stimulus, and it is possible that the mechanism may be explained by vibration stimulation affecting motor neuron excitability, and/or fast twitch fibre recruitment (Rittweger et al., 2000). It is known that this adaptation is similar to resistance training (Bosco et al., 1998; Delecluse et al., 2003; Aagaard et al., 2002; Bosco et al., 2000). When 
vibration is applied to muscle or muscle tendon, Ia afferent is stimulated and this leads to the occurrence of a myotatic reflex contraction which is known as tonic vibration reflex (Burke and Schiller, 1976; Hagbarth and Eklund, 1966; Romaiguere et al., 1993).

An enhancement of the tonic vibration reflex, proposed improvements in neuron excitability and motor unit recruitment of the muscle are cited as reasons for improvement in strength and power output (Cloak et al., 2016). Other mechanisms affecting vibratory stimulus are accepted as muscle temperature (Cochrane et al., 2008), blood flow (Kerschan-Schindl et al., 2001) and post activation potentiation (PAP) (Cochrane et al., 2010).

Frequency, amplitude, acceleration and duration of vibration are known as the loading parameters of WBV training (Marín et al., 2012). Selected amplitude and frequency lead to contradictory results on many occasions. Luo et al. (2005) recommended that the most effective frequencies to achieve greater muscle activation are between 30 and $50 \mathrm{~Hz}$. Contrary to Luo et al. (2005), Cardinale and Lim (2003) reported that the $30 \mathrm{~Hz}$ vibration frequency was responsible for providing greater activation of the VL muscle when compared to 40 and $50 \mathrm{~Hz}$. On the other hand, Hazell et al. (2007) argued that to obtain high muscular activity, higher frequencies and amplitudes were needed.

An important factor affecting results of WBV treatments may be training status and experience in sports of the subjects. While some researchers have argued that WBV treatments have no positive effects in enhancing neuromuscular performance of well-trained athletes due to their already having highly developed muscular characteristics, such as high levels of reflex sensitivity, fast-twitch fibre recruitment, motor neuron excitability, and stiffer muscle-tendon units (Delecluse et al., 2005; Bullock et al., 2008), others have suggested that WBV exercise enhances neuromuscular performance of well-trained athletes safely and effectively (Cardinale and Erskine, 2008; George et al., 26; Dallas and Kirialanis, 2013).

Many studies can be found in the literature which are conducted on well-trained athletes competing in different sports branches (Delecluse et al., 2005; Annio et al., 2007; Cochrane and Hawke, 2007; Cochrane and Stannard, 2005; Fagnani eta al., 2006; Kinser et al., 2008; Mahieu et al., 2006). The sample groups of these studies consisted of well-trained volleyball players, basketball players, track and field athletes, soccer players (Padulo et al., 2014), sprinters (Delecluse et al., 2005), ballet dancers (Annio et al., 2007), gymnasts (Kinser et al., 2008), skiers (Mahieu et al., 2006), hockey players (Cochrane and Stannard, 2005) and climbers (Cochrane and Hawke, 2007). These investigations have shown that WBV improves sports performance.

There are only two studies focusing on WBV effects on sports performance of swimmers. One of them showed that upper-body vibration applied to master swimmers was an alternative method to warm-up exercises (Nepocatych et al., 2010). The other reported that vibration was not an effective method to improve range of motion of well-trained women synchronised swimmers (Sands et al., 2008).

It is known that swimming is a non-weight-bearing sport. Because of this speciality, swimming differs from weight-bearing sports such as soccer and basketball. Athletes from weight-bearing sports are already adapted to training and competing under the influence of gravitational forces.

In view of this point, we aimed to investigate the acute effects of WBV treatments on neuromuscular activity with different frequencies and amplitude combinations during unloaded static and dynamic squat exercises of well-trained male athletes competing in basketball, soccer and swimming by using the sEMG method.

We hypothesized that well-trained athletes specialized in basketball, soccer and swimming may show different neuromuscular responses to WBV treatments at the same frequencies and amplitudes during unloaded static and dynamic squat exercises.

\section{Method}

All testing procedures were performed in the Movement and Motor Control Laboratory of the Sport Sciences Faculty of Anadolu University and all testing evaluations were conducted at similar times of the day (14:00 - 17:00) to avoid any possible biased study results due to diurnal variation. In order to examine the effects of WBV on muscular activities of athletes, the sEMG activity of six leg muscles - TA, GM, VM, RF, VL and BF- were analyzed. Participants were assigned to receive different WBVs in a randomized order to avoid order effect on study results.

\subsection{Subjects}

Twenty well-trained male athletes ( 7 soccer players, 7 basketball players and 6 swimmers) having no injuries, previous neurological irregularities or contraindications to WBV were recruited as participants. Demographic characteristics of the participants are presented in Table 1.

Subjects were required not to participate in vigorous physical activity (especially related to the lower body), nor to consume food or beverages containing caffeine or any other types of stimulants or ergogenic aid for at least 48 hours 
prior to the testing session. All participants were informed about the procedures, purpose, and risks of the study. Then, they signed an informed written consent approved by the Medical Ethics Committee of the Medical Faculty of the local university (approval No. 20478486-42) in accordance with the Declaration of Helsinki. All participants completed all phases of the experimental procedure without complaint regarding WBV treatments and sEMG measurements. Table 1 shows that the groups were homogeneous in terms of age, mass, training experience and training volume.

Table 1. Demographic characteristics of the participants

\begin{tabular}{llllll}
\hline & $\begin{array}{l}\text { Soccer } \\
(\mathrm{n}=7)\end{array}$ & $\begin{array}{l}\text { Basketball } \\
(\mathrm{n}=7)\end{array}$ & $\begin{array}{l}\text { Swimming } \\
(\mathrm{n}=6)\end{array}$ & $\mathrm{p}$ & $\mathrm{F}$ \\
\hline Age (years) & $20.8 \pm 1.7$ & $20.2 \pm 1.5$ & $19.2 \pm 1.1$ & 0.186 & 1.86 \\
Height (m) & $1.76 \pm 0.02^{*}$ & $1.87 \pm 0.05^{* \dagger}$ & $1.78 \pm 0.02 \dagger$ & $\begin{array}{l}<0.001^{*} \\
0.002 \dagger\end{array}$ & $19.2 \#$ \\
Mass (kg) & $72.0 \pm 7.1$ & $79.8 \pm 5.5$ & $72.1 \pm 7.1$ & 0.102 & 2.62 \\
Training Experience (years) & $9.71 \pm 2.63$ & $9.14 \pm 1.46$ & $11.3 \pm 2.7$ & 0.294 & 1.32 \\
Training Volume (hour/week) & $8.86 \pm 3.31$ & $8.57 \pm 1.84$ & $8.16 \pm 2.03$ & 0.901 & 0.105 \\
\hline
\end{tabular}

Values are expressed as mean \pm SD. F: One-way ANOVA F value. \#: statistically significant ANOVA result at the level of $\mathrm{p} \leq 0.05$. Mean values having the same symbol $(*, \dagger)$ are statistically different from each other at the significance level of $\mathrm{p} \leq 0.05$.

\subsection{Positioning Procedure}

The body position that each participant used during WBV trials was adjusted in the process of familiarization. According to Ritzmann et al. (2013) the most beneficial static squat knee joint angle for knee extensor muscles is $120^{\circ}$ with normal stance conditions (approximate shoulder width) and heels in contact with the platform. Therefore, in the current study, participants stood on the WBV platform in a comfortable static squat position with their knees flexed at $120^{\circ}$ measured by manual goniometer (Lafayette Instrument ${ }^{\odot}$ Model: LA-01135, USA). Then, participants were asked to maintain this static position and directly look towards the wall in front of them to keep the distance from chin to chest throughout the movement. During this position, a hard plastic stick with a special set-up (Figure 1) was positioned in parallel to the floor at a height that allowed a slight contact with the top of the head. Each participant kept this position by feeling slight contact with the stick during all static squats (Figure 1). Foot position of each participant was marked on the WBV platform. Participants were required to maintain their own foot position during all WBV trials.
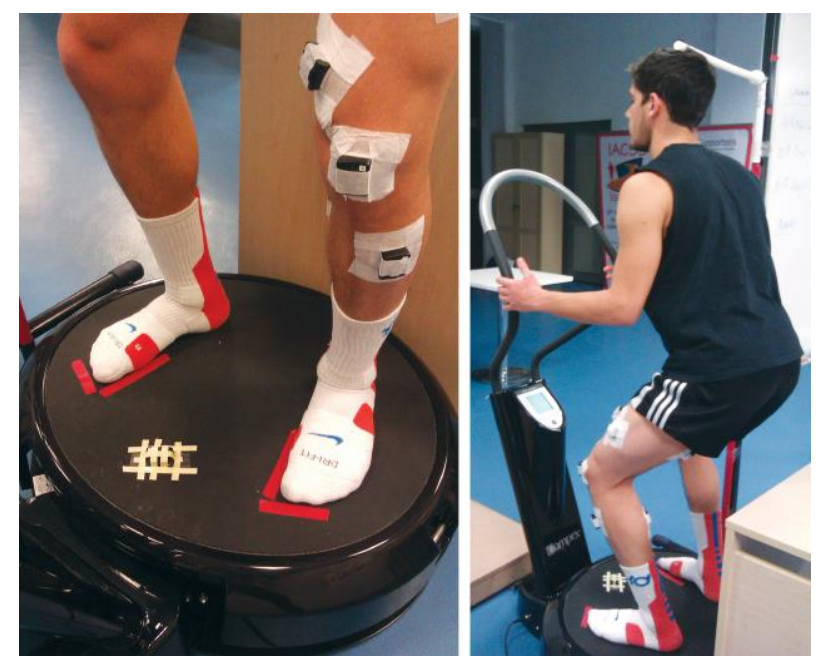

Figure 1. The body position during treatments.

The smallest adverse effects on the basis of head acceleration and mechanical impedance occur in the body position with small knee flexion angles $\left(26^{\circ}-30^{\circ}\right)$ during WBV (Abercromby et al., 2007). Therefore, in the current study, the participants maintained their body position with knee joint angle greater than $30^{\circ}$ during dynamic squatting. Accordingly, participants performed the dynamic squat with a $60^{\circ}$ range of motion (ROM) (between $90^{\circ}$ and $150^{\circ}$ ). An obstacle was placed behind the WBV device so that when the participants squatted down to the $90^{\circ}$ knee joint angle, 
their hips made slight contact with this obstacle. The $150^{\circ}$ knee joint angle limit was adjusted by the aforementioned set-up that was used in the static squat condition. This special set-up was designed in order to allow participants to perform the dynamic squats within the predetermined ROM. Each participant performed dynamic squat repetitions at a constant pace of $3 \mathrm{~s}$ down and $2 \mathrm{~s}$ up. This constant pace was counted out loud second by second simultaneously with the time display of the WBV device by one of the researchers (the same researcher for each subject).

Participants were strictly warned not to hold the handles of the WBV device during static and dynamic squats, since possible pulling of the handles of the WBV device during squats could reduce the amount of body weight transferred to the legs. Therefore, participants were asked to keep their elbows at a flexion angle of $\sim 90^{\circ}$ and touch the handles of the WBV device slightly with their palms just to maintain their balance. During the WBV treatments a dampening mat was not used and all of the subjects wore athletic socks.

\subsection{Familiarization Procedure}

Prior to the experimental protocol participants performed familiarization trials to acclimate to the body postures, pacing of the dynamic squat and sensation of WBV. Participants were given a demonstration of proper technique for the squat position and were allowed to practice until they performed the squats correctly. They performed several dynamic squats on the WBV device receiving no vibration with a repetition pace of 3 seconds down and 2 seconds up. Afterwards, four 10-second WBV trials (two for static and two for dynamic squats) were performed in randomly chosen frequency-amplitude combinations separated by 1-minute rest intervals.

\subsection{Surface EMG (sEMG) Recording}

sEMG was recorded from TA, GM, VM, RF, VL and BF during maximal voluntary isometric contractions (MVIC), and static and dynamic squats. These muscles were selected because they are primary agonist and antagonist muscles for the static and dynamic squat for lower extremities. Bipolar bar electrodes $(99.9 \% \mathrm{Ag}, 10-\mathrm{mm}$ length $\times 1-\mathrm{mm}$ width, 10-mm spacing; CMRR: > 80 dB; Trigno ${ }^{\mathrm{TM}}$ Wireless DelSys EMG System, Inc., Boston, MA) were applied to lightly abraded, washed skin over the respective muscle belly, parallel to the pennation angle. Each electrode was adhered to skin with soft medical adhesive plaster in case oscillation caused the electrode to drift away from the skin during WBV. sEMG electrode placement for each muscle was done according to European recommendations for the noninvasive assessment of muscles for surface electromyography (Hermens et al., 2000). The sEMG signal was sampled at $2000 \mathrm{~Hz}$ and was preamplified by a gain of $1000 \mathrm{~Hz}$. The sEMG system had a 20-500 Hz frequency band, intraelectrode impedance was $6 \mathrm{kOhm}$ maximum, CMRR (Common Mode Rejection Ratio) was $95 \mathrm{~dB}$ and speed of analog-digital converter was 16-bit. A normalization process was performed in order to determine the sEMG values (root-meansquare, RMS). sEMG-data processing was performed using MatLab software (MathWorks R2011a). The sEMG signals were band-pass filtered (20-450 Hz) and smoothed using RMS and a 100-millisecond moving-window function.

\section{5 sEMG Recording During Maximal Voluntary Isometric Contraction}

MVIC is known as the best method for the sEMG normalization process (Burden, 2010). Therefore, all sEMG signals were normalized to the maximum sEMG signal recorded during MVICs and referred to as percentage of MVIC (\%MVIC). The subjects performed 1 trial to figure out the task for the MVIC tests, and thereafter they performed 3 repetitions of 5 seconds' duration.

For each MVIC trial, the maximum value obtained from 5 seconds' maximum effort was recorded and the maximum RMS values of 3 MVIC trials were used for the normalization of the sEMG data obtained during the WBV treatments. For each muscle, the average of the 3 trials expressed as \%MVIC and was used for data analysis (Begalle et al., 2012; Harput et al., 2014). During the MVIC tests, subjects were supplied with standardized verbal encouragements to produce maximum effort. A 2-minute rest was given between contractions.

\section{6 sEMG Recording During the WBV Treatments}

The vibration stimulus of the WBV device (Compex ${ }^{\circledR}$ WINPLATE, Swiss) used in this study consisted of uniform vertical oscillations. Fifteen minutes after the completion of the MVIC assessment protocol, baseline sEMG measurements were recorded on the WBV device during static and dynamic squats while receiving no vibration $(0 \mathrm{~Hz}$, $0 \mathrm{~mm})$. Afterwards, participants were randomly exposed to $6 \mathrm{WBV}$ treatments with different frequency $(30-35-40 \mathrm{~Hz})$ and amplitude (2-4 $\mathrm{mm}$ ) combinations during static and dynamic squat positions (Figure 1). The sEMG signals were recorded once the participants had taken up the correct position on the WBV platform. Each WBV treatment was $30 \mathrm{~s}$ in length. During the first 3-4 seconds, muscle activity was recorded without WBV stimulus. Then, the WBV device was turned on and sEMG was recorded for the next 30 seconds. All data were collected in a single testing session on the dominant leg in a randomized order. In order to eliminate any potential fatigue and/or residual WBV effect on muscles, 5-minute passive rest periods between treatments were provided (Hazell et al., 2007). Participants were blinded to the WBV frequency and amplitude. Schematic representation of the study design is demonstrated in Figure 1. 


\section{Results}

\subsection{Statistics and Data Analysis}

Statistical analyses were performed using the SPSS 20.0 software. Natural-logarithmical (log) transformations were performed on the data in order to meet the assumption of homogeneity of variances between independent groups, and to make the distribution of non-normal data normal (Keene, 1995). The normality of log-transformed data was checked by Shapiro-Wilk test and kurtosis/skewness values. The homogeneity of variance assumption was checked by Levene's test. Then, parametric statistical tests were performed using log-transformed data.

The contraction types (static-dynamic) performed during WBV and 7 combinations of WBV $(0 \mathrm{~mm}-0 \mathrm{~Hz}, 2 \mathrm{~mm}-30 \mathrm{~Hz}$, $2 \mathrm{~mm}-35 \mathrm{~Hz}, 2 \mathrm{~mm}-40 \mathrm{~Hz}, 4 \mathrm{~mm}-30 \mathrm{~Hz}, 4 \mathrm{~mm}-35 \mathrm{~Hz}, 4 \mathrm{~mm}-40 \mathrm{~Hz})$ constituted the within-subject factors, and different sports branches (soccer, basketball, swimming) constituted the between-subject factors of the study. A $3 \times 2 \times 7$ (Sport Branch $\times$ Contraction Type $\times$ WBV) mixed design analysis of variance (ANOVA) was used for each muscle in order to determine the main and interaction effects of each factor on sEMG. Intra-group and inter-group comparisons for simple effects were performed using one-factor within-subject design and one-factor between-subject design ANOVA, respectively, with the post-hoc Fisher's LSD test. Confidence interval adjustment was not performed for multiple pairwise comparisons to avoid loss of statistical power (Cloak et al., 2016; Rønnestad, 2009). Unbiased effect size of the difference (Hedges' $\mathrm{d}$; $\mathrm{d}<0.2$ trivial, $0.2 \leq \mathrm{d}<0.5$ small, $0.5 \leq \mathrm{d} \leq 0.8$ moderate, $\mathrm{d}>0.8$ large effect size) was also reported. Statistical significance level was set at $\mathrm{p} \leq 0.05$ for all analyses.

Effects of WBV treatments on lower extremity muscles of the soccer players, basketball players and swimmers presented in the tables show a lot of negative \% difference values. This means that for example in TA-S muscular activation value during $2 \mathrm{~mm}-30 \mathrm{~Hz}$ WBV, basketball players were more affected by WBV than soccer players. Mean percentage change of difference and pairwise comparison values related to the test are shown in Table 2-6.

Table 2. Statistical analysis for TA during all treatments

\begin{tabular}{|c|c|c|c|c|c|c|c|c|c|c|}
\hline & \multirow[b]{2}{*}{ A- $f$} & \multicolumn{3}{|c|}{$\begin{array}{l}\text { SOCCER (1) } \\
\text { BASKETBALL (2) }\end{array}$} & \multicolumn{3}{|c|}{$\begin{array}{l}\text { SOCCER (1) } \\
\text { SWIMMING (2) }\end{array}$} & \multicolumn{3}{|c|}{$\begin{array}{l}\text { BASKETBALL (1) } \\
\text { SWIMMING (2) }\end{array}$} \\
\hline & & $\% \Delta$ & $\mathrm{p}$ & $\mathrm{d}$ & $\% \Delta$ & $\mathrm{p}$ & $\mathrm{d}$ & $\% \Delta$ & $\mathrm{p}$ & $\mathrm{d}$ \\
\hline \multirow{7}{*}{ TA-S } & $0 \mathrm{~mm}-0 \mathrm{~Hz}$ & $-69,7$ & 0,059 & $-1,12$ & -86.1 & 0.005 & -2.30 & -54.3 & 0.280 & -0.588 \\
\hline & $2 \mathrm{~mm}-30 \mathrm{~Hz}$ & $-74,8$ & 0,043 & $-1,19$ & -68.0 & 0.081 & -1.10 & 27.1 & 0.751 & -0.169 \\
\hline & $2 \mathrm{~mm}-35 \mathrm{~Hz}$ & $-72,9$ & 0,013 & $-1,56$ & -54.6 & 0.267 & -0.679 & 67.8 & 0.474 & 0.384 \\
\hline & $2 \mathrm{~mm}-40 \mathrm{~Hz}$ & $-32,8$ & 0,492 & $-0,355$ & -47.2 & 0.339 & -0.517 & -21.3 & 0.736 & -0.179 \\
\hline & $4 \mathrm{~mm}-30 \mathrm{~Hz}$ & $-64,1$ & 0,123 & $-0,830$ & -76.6 & 0.027 & -1.32 & -34.7 & 0.533 & -0.333 \\
\hline & $4 m m-35 H z$ & $-24,1$ & 0,635 & 0,106 & -15.6 & 0.777 & -0.150 & 11.2 & 0.846 & 0.103 \\
\hline & $4 \mathrm{~mm}-40 \mathrm{~Hz}$ & $-39,7$ & 0,237 & 0,335 & -15.6 & 0.731 & -0.182 & 39.9 & 0.427 & 0.427 \\
\hline \multirow{7}{*}{ TA-D } & $0 \mathrm{~mm}-0 \mathrm{~Hz}$ & $-43,7$ & 0,358 & $-0,479$ & $-63,2$ & 0,089 & $-0,946$ & $-34,6$ & 0,305 & $-0,534$ \\
\hline & $2 \mathrm{~mm}-30 \mathrm{~Hz}$ & $-17,4$ & 0,750 & $-0,163$ & $-21,0$ & 0,696 & $-0,208$ & $-4,28$ & 0,947 & $-0,035$ \\
\hline & $2 \mathrm{~mm}-35 \mathrm{~Hz}$ & $-20,0$ & 0,764 & $-0,154$ & $-26,6$ & 0,621 & $-0,263$ & $-8,34$ & 0,886 & $-0,076$ \\
\hline & $2 \mathrm{~mm}-40 \mathrm{~Hz}$ & $-14,0$ & 0,787 & $-0,139$ & $-4,84$ & 0,925 & $-0,050$ & 10,6 & 0,865 & 0,090 \\
\hline & $4 \mathrm{~mm}-30 \mathrm{~Hz}$ & $-0,436$ & 0,994 & $-0,004$ & 17,0 & 0,788 & 0,143 & 17,5 & 0,809 & 0,128 \\
\hline & $4 \mathrm{~mm}-35 \mathrm{~Hz}$ & $-31,5$ & 0,482 & $-0,363$ & $-9,19$ & 0,851 & $-0,100$ & 32,6 & 0,571 & 0,303 \\
\hline & $4 \mathrm{~mm}-40 \mathrm{~Hz}$ & $-48,4$ & 0,299 & $-0,544$ & $-42,0$ & 0,374 & $-0,479$ & 12,5 & 0,803 & 0,132 \\
\hline
\end{tabular}

$*_{p} \leq 0.05$, Soccer $n=7$, Basketball $n=7$, Swimming=6. TA-S = Tibialis anterior during static squat, TA-D = Tibialis anterior during dynamic squat, A- $f=$ Amplitude and frequency of TVV, $\% \Delta=$ percentage difference between branch (1) and branch (2), $d=$ unbiased effect size (Hedges' d).

The highest muscular activity was determined in TA muscle of the swimmers compared with soccer players during static squatting at $4 \mathrm{~mm}-30 \mathrm{~Hz}$. However, the lowest muscular activity was determined in TA muscle of the basketball players compared with soccer players during static squatting at 2 mm-35 Hz. During dynamic squatting no statistically significant difference in TA muscle was detected when sports branches were compared with each other (see Table 2). During both dynamic and static squatting no statistically significant difference in GM muscle was detected when sports branches were compared with each other (see Table 3). During both dynamic and static squatting no statistically significant difference in VM muscle was detected when sports branches were compared with each other (see Table 4). 
The highest muscular activity was determined in VL muscle of the basketball players compared with soccer players during static squatting at $4 \mathrm{~mm}-40 \mathrm{~Hz}$. However, the lowest muscular activity was determined in VL muscle of the swimmers compared with soccer players during static squatting at $2 \mathrm{~mm}-40 \mathrm{~Hz}$. During dynamic squatting the highest muscular activity was determined in VL muscle of the basketball players compared with swimmers at $4 \mathrm{~mm}-40 \mathrm{~Hz}$. However, the lowest muscular activity was determined in VL muscle of the basketball players compared with soccer players during static squatting at $2 \mathrm{~mm}-40 \mathrm{~Hz}$ (see Table 5).

During both dynamic and static squatting no statistically significant difference in BF muscle was detected when sports branches were compared with each other (see Table 6). During both dynamic and static squatting no statistically significant difference in BF muscle was detected when sports branches were compared with each other (see Table7).

Table 3. Statistical analysis for GM during all treatments.

\begin{tabular}{|c|c|c|c|c|c|c|c|c|c|c|}
\hline & \multirow[b]{3}{*}{ A- $f$} & \multirow{2}{*}{\multicolumn{3}{|c|}{$\begin{array}{l}\text { SOCCER (1) } \\
\text { BASKETBALL (2) }\end{array}$}} & \multirow{2}{*}{\multicolumn{3}{|c|}{$\begin{array}{l}\text { SOCCER (1) } \\
\text { SWIMMING (2) }\end{array}$}} & \multirow{2}{*}{\multicolumn{3}{|c|}{$\begin{array}{l}\text { BASKETBALL (1) } \\
\text { SWIMMING (2) }\end{array}$}} \\
\hline & & & & & & & & & & \\
\hline & & $\% \Delta$ & $\mathrm{p}$ & $\mathrm{d}$ & $\% \Delta$ & $\mathrm{p}$ & $\mathrm{d}$ & $\% \Delta$ & $\mathrm{p}$ & $\mathrm{d}$ \\
\hline \multirow{7}{*}{ GM-S } & $0 \mathrm{~mm}-\mathrm{OHz}$ & $-19,6$ & 0,436 & $-0,404$ & $-17,6$ & 0,488 & $-0,371$ & 2,51 & 0,928 & 0,048 \\
\hline & $2 \mathrm{~mm}-30 \mathrm{~Hz}$ & 0,016 & $>0.999$ & $<0.001$ & $-6,25$ & 0,871 & $-0,086$ & $-6,26$ & 0,853 & $-0,098$ \\
\hline & $2 \mathrm{~mm}-35 \mathrm{~Hz}$ & 62,5 & 0,271 & 0,577 & 68,3 & 0,365 & 0,489 & 3,55 & 0,933 & 0,044 \\
\hline & $2 \mathrm{~mm}-40 \mathrm{~Hz}$ & 56,2 & 0,309 & 0,532 & 54,5 & 0,387 & 0,466 & $-1,08$ & 0,979 & $-0,014$ \\
\hline & $4 \mathrm{~mm}-30 \mathrm{~Hz}$ & 70,4 & 0,302 & 0,540 & 42,5 & 0,527 & 0,738 & $-16,4$ & 0,682 & $-0,218$ \\
\hline & $4 \mathrm{~mm}-35 \mathrm{~Hz}$ & 38,6 & 0,528 & 0,325 & 37,1 & 0,594 & 0,284 & $-1,11$ & 0,981 & $-0,013$ \\
\hline & $4 m m-40 H z$ & $-41,1$ & 0,367 & $-0,469$ & 26,0 & 0,682 & 0,218 & 114 & 0,159 & 0,783 \\
\hline \multirow{7}{*}{ GM-D } & $0 \mathrm{~mm}-0 \mathrm{~Hz}$ & 23,5 & 0,565 & 0,296 & 34,5 & 0,405 & 0,448 & 8,92 & 0,838 & 0,108 \\
\hline & $2 \mathrm{~mm}-30 \mathrm{~Hz}$ & $-7,09$ & 0,790 & $-0,136$ & 8,58 & 0,626 & 0,251 & 16,9 & 0,570 & 0,303 \\
\hline & $2 \mathrm{~mm}-35 \mathrm{~Hz}$ & 6,00 & 0,809 & 0,124 & $-9,90$ & 0,720 & $-0,190$ & $-15,0$ & 0,590 & $-0,287$ \\
\hline & $2 \mathrm{~mm}-40 \mathrm{~Hz}$ & 34,6 & 0,436 & 0,403 & 49,5 & 0,243 & 0,638 & 11,1 & 0,736 & 0,179 \\
\hline & $4 \mathrm{~mm}-30 \mathrm{~Hz}$ & 25,6 & 0,599 & 0,270 & 41,5 & 0,497 & 0,364 & 12,6 & 0,709 & 0,198 \\
\hline & $4 \mathrm{~mm}-35 \mathrm{~Hz}$ & 19,5 & 0,611 & 0,262 & 28,3 & 0,577 & 0,316 & 7,36 & 0,882 & 0,079 \\
\hline & $4 \mathrm{~mm}-40 \mathrm{~Hz}$ & $-29,7$ & 0,489 & $-0,358$ & 8,44 & 0,863 & 0,091 & 54,2 & 0,398 & 0,455 \\
\hline
\end{tabular}

${ }^{*} \mathrm{p} \leq 0.05$, Soccer $\mathrm{n}=7$, Basketball $\mathrm{n}=7$, Swimming $=6$. GM-S $=$ Gastrocnemius medialis during static squat, GM-D = Gastrocnemius medialis during dynamic squat, $\mathrm{A}-\mathrm{f}=$ Amplitude and frequency of $\mathrm{TVV}, \% \Delta=$ percentage difference between branch (1) and branch (2), d = unbiased effect size (Hedges' d). 
Table 4. Statistical analysis for VM during all treatments

\begin{tabular}{|c|c|c|c|c|c|c|c|c|c|c|}
\hline & \multirow[b]{3}{*}{ A- $f$} & \multirow{2}{*}{\multicolumn{3}{|c|}{$\begin{array}{l}\text { SOCCER (1) } \\
\text { BASKETBALL (2) }\end{array}$}} & \multirow{2}{*}{\multicolumn{3}{|c|}{$\begin{array}{l}\text { SOCCER (1) } \\
\text { SWIMMING (2) }\end{array}$}} & \multirow{2}{*}{\multicolumn{3}{|c|}{$\begin{array}{l}\text { BASKETBALL (1) } \\
\text { SWIMMING (2) }\end{array}$}} \\
\hline & & & & & & & & & & \\
\hline & & $\% \Delta$ & $\mathrm{p}$ & $\mathrm{d}$ & $\% \Delta$ & $\mathrm{p}$ & d & $\% \Delta$ & $\mathrm{p}$ & d \\
\hline \multirow{7}{*}{ VM-S } & $0 \mathrm{~mm}-\mathrm{OHz}$ & $-1,17$ & 0,960 & $-0,026$ & $-6,02$ & 0,803 & $-0,132$ & $-4,91$ & 0,719 & $-0,191$ \\
\hline & $2 \mathrm{~mm}-30 \mathrm{~Hz}$ & $-14,6$ & 0,642 & $-0,239$ & $-30,7$ & 0,320 & $-0,539$ & $-18,8$ & 0,351 & $-0,505$ \\
\hline & $2 \mathrm{~mm}-35 \mathrm{~Hz}$ & $-6,23$ & 0,867 & $-0,087$ & $-21,4$ & 0,571 & $-0,302$ & $-16,2$ & 0,446 & $-0,409$ \\
\hline & $2 \mathrm{~mm}-40 \mathrm{~Hz}$ & $-15,9$ & 0,640 & $-0,240$ & $-27,5$ & 0,433 & $-0,421$ & $-13,8$ & 0,592 & $-0,286$ \\
\hline & $4 \mathrm{~mm}-30 \mathrm{~Hz}$ & $-24,6$ & 0,428 & $-0,410$ & $-36,9$ & 0,224 & $-0,666$ & $-16,3$ & 0,465 & $-0,392$ \\
\hline & $4 m m-35 H z$ & $-18,2$ & 0,586 & $-0,280$ & $-35,6$ & 0,283 & $-0,584$ & $-21,3$ & 0,322 & $-0,537$ \\
\hline & $4 \mathrm{~mm}-40 \mathrm{~Hz}$ & $-9,62$ & 0,783 & $-0,141$ & $-19,3$ & 0,569 & $-0,304$ & $-10,7$ & 0,715 & $-0,194$ \\
\hline \multirow{7}{*}{ VM-D } & $0 \mathrm{~mm}-\mathrm{OHz}$ & $-12,4$ & 0,580 & $-0,284$ & $-7,24$ & 0,647 & $-0,244$ & 5,83 & 0,804 & 0,125 \\
\hline & $2 \mathrm{~mm}-30 \mathrm{~Hz}$ & $-8,82$ & 0,739 & $-0,170$ & 5,02 & 0,850 & 0,100 & 15,2 & 0,562 & 0,309 \\
\hline & $2 \mathrm{~mm}-35 \mathrm{~Hz}$ & $-9,40$ & 0,732 & $-0,175$ & $-2,46$ & 0,931 & $-0,046$ & 7,66 & 0,756 & 0,165 \\
\hline & $2 \mathrm{~mm}-40 \mathrm{~Hz}$ & $-5,19$ & 0,857 & $-0,092$ & $-13,1$ & 0,658 & $-0,235$ & $-8,33$ & 0,718 & $-0,192$ \\
\hline & $4 \mathrm{~mm}-30 \mathrm{~Hz}$ & 7,24 & 0,786 & 0,139 & 8,41 & 0,712 & 0,168 & 1,09 & 0,962 & 0,025 \\
\hline & $4 \mathrm{~mm}-35 \mathrm{~Hz}$ & $-10,0$ & 0,716 & $-0,187$ & $-15,9$ & 0,583 & $-0,293$ & $-6,50$ & 0,743 & $-0,174$ \\
\hline & $4 \mathrm{~mm}-40 \mathrm{~Hz}$ & 7,54 & 0,819 & 0,117 & 10,4 & 0,767 & 0,157 & 2,65 & 0,903 & 0,064 \\
\hline
\end{tabular}

$*_{p} \leq 0.05$, Soccer $n=7$, Basketball $n=7$, Swimming=6. VM-S = Vastus medialis during static squat, VM-D = Vastus medialis during dynamic squat, $\mathrm{A}-\mathrm{f}=$ Amplitude and frequency of $\mathrm{TVV}, \% \Delta=$ percentage difference between branch (1) and branch (2), $\mathrm{d}=$ unbiased effect size (Hedges' d).

Table 5. Statistical analysis for VL during all treatments

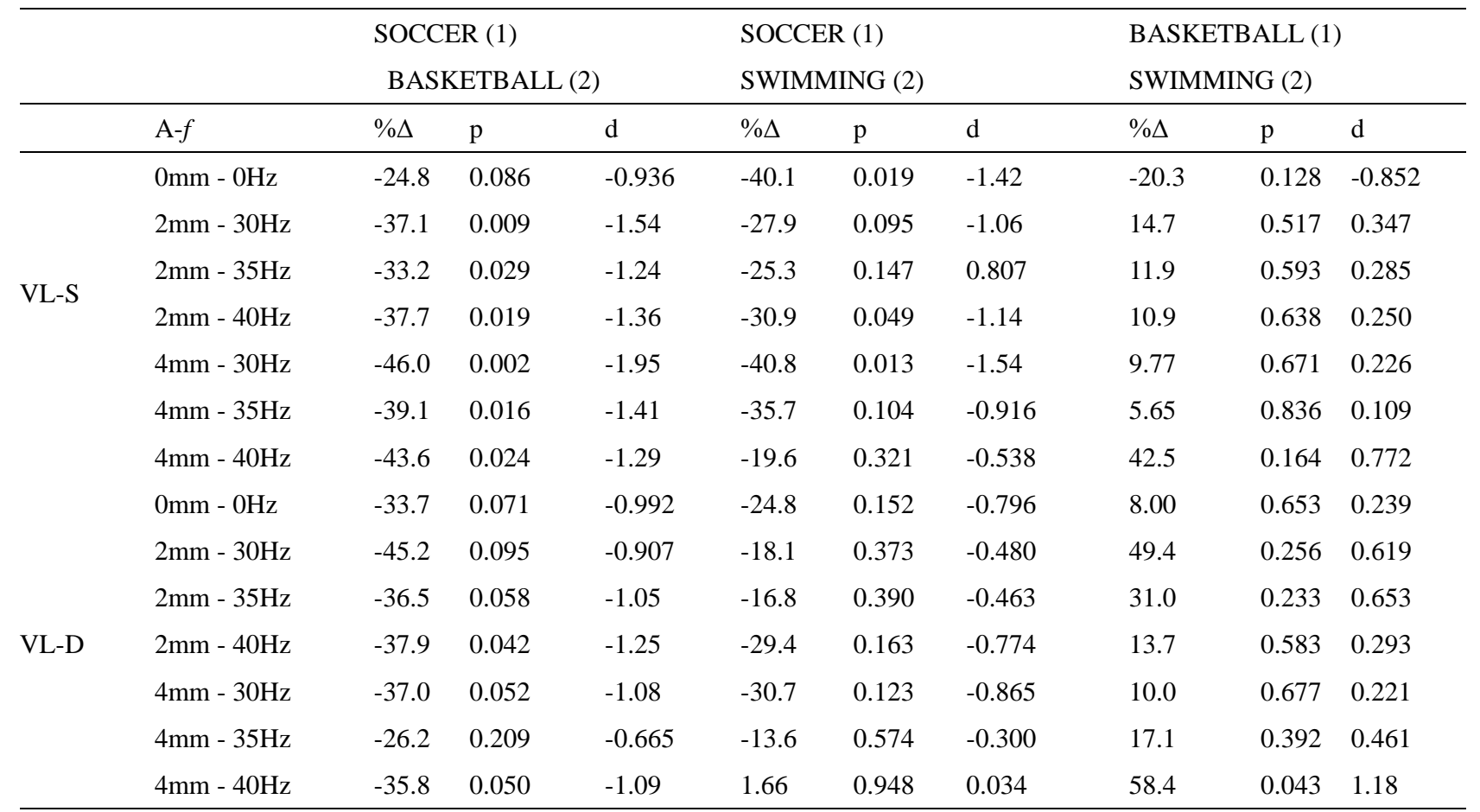

${ }^{*} \mathrm{p} \leq 0.05$, Soccer $\mathrm{n}=7$, Basketball $\mathrm{n}=7$, Swimming=6. VL-S = Vastus lateralis during static squat, VL-D = Vastus lateralis during dynamic squat, $\mathrm{A}-\mathrm{f}=\mathrm{Amplitude}$ and frequency of TVV, $\% \Delta=$ percentage difference between branch (1) and branch (2), d = unbiased effect size (Hedges' d). 
Table 6. Statistical analysis for RF during all treatments

\begin{tabular}{|c|c|c|c|c|c|c|c|c|c|c|}
\hline & \multirow[b]{3}{*}{ A- $f$} & \multicolumn{3}{|c|}{ SOCCER (1) } & \multicolumn{3}{|c|}{ SOCCER (1) } & \multicolumn{3}{|c|}{ BASKETBALL (1) } \\
\hline & & \multicolumn{3}{|c|}{ BASKETBALL (2) } & \multicolumn{3}{|c|}{ SWIMMING (2) } & \multicolumn{3}{|c|}{ SWIMMING (2) } \\
\hline & & $\% \Delta$ & $\mathrm{p}$ & d & $\% \Delta$ & $\mathrm{p}$ & $\mathrm{d}$ & $\% \Delta$ & $\mathrm{p}$ & d \\
\hline \multirow{7}{*}{ RF-S } & $0 \mathrm{~mm}-\mathrm{OHz}$ & $-34,1$ & 0,187 & $-0,700$ & $-26,8$ & 0,440 & $-0,415$ & 11,1 & 0,774 & 0,152 \\
\hline & $2 \mathrm{~mm}-30 \mathrm{~Hz}$ & $-36,5$ & 0,146 & $-0,778$ & $-41,6$ & 0,191 & $-0,795$ & $-8,02$ & 0,845 & $-0,104$ \\
\hline & $2 \mathrm{~mm}-35 \mathrm{~Hz}$ & $-12,8$ & 0,602 & $-0,270$ & $-16,4$ & 0,541 & $-0,327$ & $-4,13$ & 0,905 & $-0,063$ \\
\hline & $2 \mathrm{~mm}-40 \mathrm{~Hz}$ & $-21,0$ & 0,363 & $-0,473$ & $-27,7$ & 0,474 & $-0,425$ & $-8,44$ & 0,847 & $-0,102$ \\
\hline & $4 \mathrm{~mm}-30 \mathrm{~Hz}$ & $-12,7$ & 0,628 & $-0,249$ & $-15,3$ & 0,632 & $-0,255$ & $-3,02$ & 0,932 & $-0,045$ \\
\hline & $4 m m-35 H z$ & $-27,1$ & 0,213 & $-0,657$ & $-24,5$ & 0,446 & $-0,409$ & 3,64 & 0,932 & 0,045 \\
\hline & $4 \mathrm{~mm}-40 \mathrm{~Hz}$ & $-33,1$ & 0,113 & $-0,854$ & $-13,5$ & 0,731 & $-0,194$ & 29,3 & 0,544 & 0,349 \\
\hline \multirow{7}{*}{ RF-D } & $0 \mathrm{~mm}-\mathrm{OHz}$ & $-27,7$ & 0,263 & $-0,587$ & $-12,0$ & 0,716 & $-0,194$ & 21,7 & 0,560 & 0,311 \\
\hline & $2 \mathrm{~mm}-30 \mathrm{~Hz}$ & $-41,6$ & 0,097 & $-0,902$ & $-11,2$ & 0,753 & $-0,167$ & 52,1 & 0,286 & 0,581 \\
\hline & $2 \mathrm{~mm}-35 \mathrm{~Hz}$ & $-38,2$ & 0,107 & $-0,873$ & $-12,3$ & 0,717 & $-0,193$ & 42,0 & 0,354 & 0,501 \\
\hline & $2 \mathrm{~mm}-40 \mathrm{~Hz}$ & $-32,2$ & 0,184 & $-0,713$ & $-16,2$ & 0,621 & $-0,263$ & 23,6 & 0,581 & 0,295 \\
\hline & $4 \mathrm{~mm}-30 \mathrm{~Hz}$ & $-21,9$ & 0,326 & $-0,512$ & $-18,7$ & 0,574 & $-0,300$ & 4,05 & 0,910 & 0,060 \\
\hline & $4 m m-35 H z$ & $-27,8$ & 0,235 & $-0,626$ & $-26,5$ & 0,418 & $-0,436$ & 1,85 & 0,958 & 0,028 \\
\hline & $4 m m-40 H z$ & $-33,3$ & 0,087 & $-0,932$ & 39,0 & 0,341 & 0,515 & 108 & 0,030 & 1,29 \\
\hline
\end{tabular}

$* p \leq 0.05$, Soccer $n=7$, Basketball $n=7$, Swimming=6. RF-S = Rectus femoris during static squat, RF-D = Rectus femoris during dynamic squat, A-f = Amplitude and frequency of TVV, $\% \Delta=$ percentage difference between branch (1) and branch (2), d = unbiased effect size (Hedges' d).

Table 7. Statistical analysis for BF during all treatments

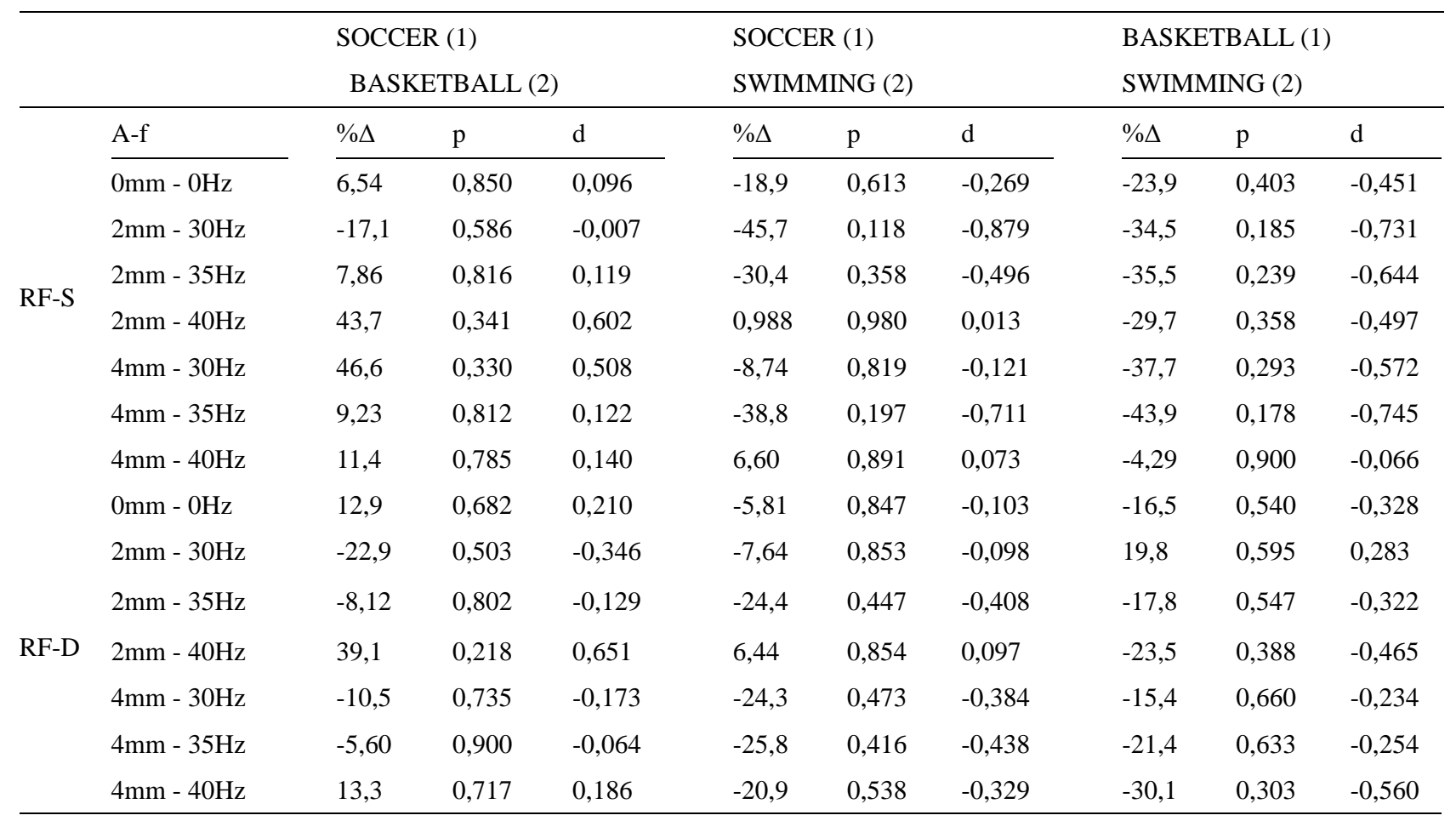

${ }^{*} \mathrm{p} \leq 0.05$, Soccer $\mathrm{n}=7$, Basketball $\mathrm{n}=7$, Swimming=6. RF-S = Biceps femoris during static squat, RF-D = Rectus femoris during dynamic squat, A-f $=$ Amplitude and frequency of TVV, $\% \Delta=$ percentage difference between branch (1) and branch (2), $\mathrm{d}=$ unbiased effect size (Hedges' d). 


\section{Discussion}

This may be the first study that focuses on WBV-induced increases in activity of the leg muscles during unloaded static and dynamic squat applied in different WBV load combinations on high level athletes from different sports branches. We concluded that the results obtained from the present study are reliable due to the fact that the groups were homogeneous in terms of age, mass, training experience and training volume. This issue is very important in the field of WBV studies. However, Cloak et al. (2016) and Ronnestad (2009) reported that elite athletes show greater increases in force output, muscle sensitivity to stimulus and balance after WBV treatments. On the other hand, Cloak et al. (2016) suggested that acute WBV may impair balance and landing stability amongst amateur soccer players due to fatigue induced by WBV treatments. In addition, Ronnestad et al. (2016) identified improved sprint performance related to perceived improvement in feeling of well-being in the legs following acute WBV in elite ice hockey players. If the athletes in the present study had shown different age, mass, training experience and training volume characteristics, the results obtained from this study could have been different.

The main findings of this study are; a) During static squat the highest muscle activation was determined in TA muscle of the swimmers compared to soccer players with $4 \mathrm{~mm}-30 \mathrm{~Hz}$ WBV application $(\% \Delta=76.6, \mathrm{p}=0.027, \mathrm{~d}=1.32)$. b) The lowest muscle activation was determined in VL muscle of swimmers compared to soccer players during static squat with $2 \mathrm{~mm}-40 \mathrm{~Hz}$ WBV $(\% \Delta=30.9, \mathrm{p}=0.049, \mathrm{~d}=1.14 \mathrm{c})$. During dynamic squat with $4 \mathrm{~mm}-40 \mathrm{~Hz} \mathrm{WBV}$, the highest muscle activity was determined in RF muscle of the basketball players compared to swimmers $(\% \Delta=108.3, p=0.030$, $\mathrm{d}=1.29)$. During dynamic squat with $2 \mathrm{~mm}-40 \mathrm{~Hz}$ WBV application the lowest muscle activation was determined in VL muscle of the swimmers compared to soccer players $(\% \Delta=37.9, \mathrm{p}=0.042, \mathrm{~d}=1.25)$.

In this study, the biggest muscle activation was determined in GM muscle of the basketball players compared to swimmers during dynamic squatting with $4 \mathrm{~mm}-40 \mathrm{~Hz}$ WBV treatment. However, this value does not differ statistically from other determined higher muscular activity also detected during dynamic squatting with $4 \mathrm{~mm}-40 \mathrm{~Hz}$ WBV application in RF muscle of the basketball players in comparison with swimmers. According to this determination, we concluded that during dynamic squatting, WBV with higher amplitudes and higher frequencies $(4 \mathrm{~mm}-40 \mathrm{~Hz})$ may be more suitable in activating the leg muscles in comparison with WBV which is applied during static squatting with higher amplitudes and higher frequencies $(4 \mathrm{~mm}-30 \mathrm{~Hz}$, in TA muscle of the swimmers). According to these results it can be said that the WBV stimulus resulted in statistically significant differences among different sports branches.

TA muscle had the biggest neuromuscular response to WBV in comparison to the other muscles during static squat position in swimmers and basketball players. According to this result, it can be said that the increase in EMG activity was very clear in the shank muscle TA proximally located from the vibration device and marginally less pronounced in the distally located thigh muscles. As the ankle and knee joint, soft tissue and bones as well as calf muscles absorbed vibration energy, closer muscles to the vibration stimulus might also have affected the magnitude of neuromuscular responses to WBV exposure (Abercromby et al., 2007; Roelants et al., 2006). This result is similar to the studies in literature (Ritzmann et al., 2013; Bressel et al., 2010). So, in this study we present that in muscles closer to the vibration exposure, the vibration stimulus is less absorbed because of muscle and segment stiffness (Mester et al., 1999).

GM muscle was affected by WBV exercise in dynamic squatting. This result may be explained by the fact that a muscle closer to the WBV source is more receptive to the vibration stimulus (Perchthaler et al., 2015).

On the other hand, increased muscular activity in TA by depending on WBV applied during static squatting is attributable to the fact that muscles with an increased muscle length or increased degree of preactivation seemed to be most affected by vibration (Roelants et al., 2006).

According to the literature, it can be assumed that muscle tendon units are stretched during WBV treatments in every WBV oscillation (Cochrane et al., 2009; Ritzmann et al., 2010). This stretch mechanism shows frequency-dependent activation of the muscle spindles and thus increased stretch reflex responses detectable in the EMG signal (Ritzmann et al., 2010). Consequently, it can be assumed that the increases in EMG activity of RF muscle during WBV were caused by the higher number of stretch reflex responses. This unexpected output may result from stimulation of stretch reflex of RF muscle by motoric abilities of basketball players which they performed by jumping on the dominant leg. Accordingly, it can be said that WBV treatments led to motor unit synchronization and motor unit (MU) recruitment thresholds in RF muscle during dynamic squat under WBV exposure because of the mechanism of WBV which stimulates stretch reflex (Roll et al., 1989).

It was observed that VL muscle was the least affected by WBV treatments during both static and dynamic squat. However, VL muscle is a receptor-bearing muscle. A receptor bearing muscle is more preactivated before the start of vibration, as muscle spindles are more sensitive to vibration during a voluntary contraction compared with a relaxed muscle (Roelants et al., 2006; Roll et al., 1989). 
Another important result of this study is determined as the fact that higher amplitudes and frequencies of WBV $(4 \mathrm{~mm}-40 \mathrm{~Hz})$ resulted in the greatest increases in muscle activity, in line with the study of Hazell et al. (2007). Effectiveness of WBV with higher amplitudes and frequencies is also reported by Roelants et al. (2006) and Hazell, Kenno and Jakobi (2010).

According to the present study, the least muscular activity is observed in soccer players. We could not explain why soccer players were only slightly affected by WBV treatments. This may be caused by the characteristics of soccer or by the soccer players who were recruited for this study.

We did not determine leg muscle mass and muscle cross sectional area (CSA) of the subjects. Results of the present study may have affected leg muscle mass and CSA of the subjects. In future studies, researchers should keep in mind these parameters.

In conclusion, this may be the first study to identify static and dynamic sEMG activity of well-trained athletes from different sports during WBV treatments. Well-trained athletes from different sports branches had statistically different neuromuscular responses to WBV treatments during static and dynamic squat. It can be said that WBV treatments are an effective way to improve acute muscular activation of well-trained athletes. However, the effectiveness of WBV treatments depend on target muscle, static or dynamic muscle contractions and frequency-amplitude combinations. Trainers or athletes should determine their WBV training loads according to target muscle. Finally, the main output of our study is that well-trained male athletes who aim to improve muscular activation should choose dynamic squat instead of static squat. In addition to this, WBV with higher amplitude and frequency is more effective in increasing lower body muscle activity. For future investigations, scientists can focus on the acute or chronic responses to WBV treatments of well-trained and untrained subjects from different sports branches.

\subsection{Acknowledgements}

This study was funded by the Anadolu University Faculty of Sports Sciences (BAP/1207S116).

\subsection{Declaration of Conflicting Interests}

There is no conflict of interest with any financial or other types of organization regarding the content of the manuscript.

\section{References}

Aagaard, P., Simonsen, E. B., Andersen, J. L., Magnusson, P., \& Dyhre-Poulsen, P. (2002). Increased rate of force development and neural drive of human skeletal muscle following resistance training. Journal of applied physiology, 93(4), 1318-1326. https://doi.org/10.1152/japplphysiol.00283.2002

Abercromby, A. F., Amonette, W. E., Layne, C. S., Mcfarlin, B. K., Hinman, M. R., \& Paloski, W. H. (2007). Vibration exposure and biodynamic responses during whole-body vibration training. Medicine and science in sports and exercise, 39(10), 1794-1800. https://doi.org/10.1249/mss.0b013e3181238a0f

Annino, G., Padua, E., Castagna, C., Di Salvo, V., Minichella, S., Tsarpela, O., ... \& D'ottavio, S. (2007). Effect of whole body vibration training on lower limb performance in selected high-level ballet students. Journal of strength and conditioning research, 21(4), 1072-1076.

Begalle, R. L., DiStefano, L. J., Blackburn, T., \& Padua, D. A. (2012). Quadriceps and hamstrings coactivation during common therapeutic exercises. Journal of athletic training, 47(4), 396-405. https://doi.org/10.4085/1062-6050-47.4.01

Bosco, C. M. C., \& Colli, R. (1998). j. Tihanyi, SP von Duvillard, and A. Viru. The influence of whole body vibration on jumping ability. Bio/. Sport, 15, 157-164.

Bosco, C., Iacovelli, M., Tsarpela, O., Cardinale, M., Bonifazi, M., Tihanyi, J., ... \& Viru, A. (2000). Hormonal responses to whole-body vibration in men. European journal of applied physiology, 81(6), 449-454. https://doi.org/10.1007/s004210050067

Bressel, E., Smith, G., \& Branscomb, J. (2010). Transmission of whole body vibration in children while standing. Clinical biomechanics, 25(2), 181-186. https://doi.org/10.1016/j.clinbiomech.2009.10.016

Bullock, N., Martin, D. T., Ross, A., Rosemond, C. D., Jordan, M. J., \& Marino, F. E. (2008). Acute effect of whole-body vibration on sprint and jumping performance in elite skeleton athletes. The Journal of Strength \& Conditioning Research, 22(4), 1371-1374. https://doi.org/10.1519/JSC.0b013e31816a44b5

Burden, A. (2010). How should we normalize electromyograms obtained from healthy participants? What we have learned from over 25 years of research. Journal of electromyography and kinesiology, 20(6), 1023-1035. https://doi.org/10.1016/j.jelekin.2010.07.004 
Burke, D. A. V. I. D., \& Schiller, H. H. (1976). Discharge pattern of single motor units in the tonic vibration reflex of human triceps surae. Journal of Neurology, Neurosurgery \& Psychiatry, 39(8), 729-741. https://doi.org/10.1136/jnnp.39.8.729

Cardinale, M., \& Erskine, J. A. (2008). Vibration training in elite sport: effective training solution or just another fad?. International journal of sports physiology and performance, 3(2), 232-239. https://doi.org/10.1123/ijspp.3.2.232

Cardinale, M., \& Lim, J. (2003). Electromyography activity of vastus lateralis muscle during whole-body vibrations of different frequencies. The Journal of Strength \& Conditioning Research, 17(3), 621-624.

Cloak, R., Lane, A., \& Wyon, M. (2016). Professional soccer player neuromuscular responses and perceptions to acute whole body vibration differ from amateur counterparts. Journal of sports science \& medicine, 15(1), 57.

Cloak, R., Nevill, A., \& Wyon, M. (2016). The acute effects of vibration training on balance and stability amongst soccer players. European journal of sport science, 16(1), 20-26. https://doi.org/10.1080/17461391.2014.973912

Cochrane, D. J., \& Hawke, E. J. (2007). Effects of acute upper-body vibration on strength and power variables in climbers. Journal of strength and conditioning research, 21(2), 527.

Cochrane, D. J., \& Stannard, S. R. (2005). Acute whole body vibration training increases vertical jump and flexibility performance in elite female field hockey players. British journal of sports medicine, 39(11), 860-865. https://doi.org/10.1136/bjsm.2005.019950

Cochrane, D. J., Loram, I. D., Stannard, S. R., \& Rittweger, J. (2009). Changes in joint angle, muscle-tendon complex length, muscle contractile tissue displacement, and modulation of EMG activity during acute whole-body vibration. Muscle \& Nerve: Official Journal of the American Association of Electrodiagnostic Medicine, 40(3), 420-429. https://doi.org/10.1002/mus.21330

Cochrane, D. J., Stannard, S. R., Firth, E. C., \& Rittweger, J. (2010). Acute whole-body vibration elicits post-activation potentiation. European journal of applied physiology, 108(2), 311. https://doi.org/10.1007/s00421-009-1215-2

Cochrane, D. J., Stannard, S. R., Sargeant, A. J., \& Rittweger, J. (2008). The rate of muscle temperature increase during acute whole-body vibration exercise. European journal of applied physiology, 103(4), 441-448. https://doi.org/10.1007/s00421-008-0736-4

Dallas, G., \& Kirialanis, P. (2013). The effect of two different conditions of whole-body vibration on flexibility and jumping performance on artistic gymnasts. Science of Gymnastics Journal, 5(2), 67-77.

Delecluse, C., Roelants, M., \& Verschueren, S. (2003). Strength increase after whole-body vibration compared with resistance training. Medicine \& Science in Sports \& Exercise, 35(6), 1033-1041. https://doi.org/10.1249/01.MSS.0000069752.96438.B0

Delecluse, C., Roelants, M., Diels, R., Koninckx, E., \& Verschueren, S. (2005). Effects of whole body vibration training on muscle strength and sprint performance in sprint-trained athletes. International journal of sports medicine, 26(8), 662-668. https://doi.org/10.1055/s-2004-830381

Fagnani, F., Giombini, A., Di Cesare, A., Pigozzi, F., \& Di Salvo, V. (2006). The effects of a whole-body vibration program on muscle performance and flexibility in female athletes. American journal of physical medicine \& rehabilitation, 85(12), 956-962. https://doi.org/10.1097/01.phm.0000247652.94486.92

Fernandez-Rio, J., Terrados, N., Fernandez-Garcia, B., \& Suman, O. E. (2010). Effects of vibration training on force production in female basketball players. The Journal of Strength \& Conditioning Research, 24(5), 1373-1380. https://doi.org/10.1519/JSC.0b013e3181d1d2b1

George, D., Vasilis, K., Vasilis, M., \& Giorgos, P. (2012). Acute effect of whole-body vibration combined with stretching on bridge performance in artistic gymnasts. Biology of Exercise, 8(2), 47-57. https://doi.org/10.4127/jbe.2012.0059

Hagbarth, K. E., \& Eklund, G. (1966). Tonic vibration reflexes (TVR) in spasticity. Brain research, 2(2), 201-203. https://doi.org/10.1016/0006-8993(66)90029-1

Harput, G., Soylu, A. R., Ertan, H., Ergun, N., \& Mattacola, C. G. (2014). Effect of gender on the quadriceps-to-hamstrings coactivation ratio during different exercises. Journal of sport rehabilitation, 23(1), 36-43. https://doi.org/10.1123/JSR.2012-0120

Hazell, T. J., Jakobi, J. M., \& Kenno, K. A. (2007). The effects of whole-body vibration on upper-and lower-body EMG during static and dynamic contractions. Applied physiology, nutrition, and metabolism, 32(6), 1156-1163. https://doi.org/10.1139/H07-116 
Hazell, T. J., Kenno, K. A., \& Jakobi, J. M. (2010). Evaluation of muscle activity for loaded and unloaded dynamic squats during vertical whole-body vibration. The Journal of Strength \& Conditioning Research, 24(7), 1860-1865. https://doi.org/10.1519/JSC.0b013e3181ddf6c8

Hermens, H. J., Freriks, B., Disselhorst-Klug, C., \& Rau, G. (2000). Development of recommendations for SEMG sensors and sensor placement procedures. Journal of electromyography and Kinesiology, 10(5), 361-374. https://doi.org/10.1016/S1050-6411(00)00027-4

Keene, O. N. (1995). The log transformation is special. Statistics in medicine, 14(8), 811-819. https://doi.org/10.1002/sim.4780140810

Kerschan-Schindl, K., Grampp, S., Henk, C., Resch, H., Preisinger, E., Fialka-Moser, V., \& Imhof, H. (2001). Wholebody vibration exercise leads to alterations in muscle blood volume. Clinical physiology, 21(3), 377-382. https://doi.org/10.1046/j.1365-2281.2001.00335.x

Kinser, A. M., Ramsey, M. W., O'bryant, H. S., Ayres, C. A., Sands, W. A., \& Stone, M. H. (2008). Vibration and stretching effects on flexibility and explosive strength in young gymnasts. Medicine \& Science in Sports \& Exercise, 40(1), 133-140. https://doi.org/10.1249/mss.0b013e3181586b13

Luo, J., McNamara, B., \& Moran, K. (2005). The use of vibration training to enhance muscle strength and power. Sports Medicine, 35(1), 23-41. https://doi.org/10.2165/00007256-200535010-00003

Mahieu, N. N., Witvrouw, E., Van de Voorde, D., Michilsens, D., Arbyn, V., \& Van den Broecke, W. (2006). Improving strength and postural control in young skiers: whole-body vibration versus equivalent resistance training. Journal of athletic training, 41(3), 286-293.

Marín, P. J., Herrero, A. J., García-López, D., Rhea, M. R., López-Chicharro, J., González-Gallego, J., \& Garatachea, N. (2012). Acute effects of whole-body vibration on neuromuscular responses in older individuals: implications for prescription of vibratory stimulation. The Journal of Strength \& Conditioning Research, 26(1), 232-239. https://doi.org/10.1519/JSC.0b013e31821d9789

Mester, J., Spitzenfeil, P., Schwarzer, J., \& Seifriz, F. (1999). Biological reaction to vibration-implications for sport. Journal of Science and Medicine in Sport, 2(3), 211-226. https://doi.org/10.1016/S1440-2440(99)80174-1

Nepocatych, S., Bishop, P. A., Balilionis, G., Richardson, M. T., \& Hubner, P. J. (2010). Acute effect of upper-body vibration on performance in master swimmers. The Journal of Strength \& Conditioning Research, 24(12), 3396-3403. https://doi.org/10.1519/JSC.0b013e3181e8a4fe

Padulo, J., Giminiani, R. D., Ibba, G., Zarrouk, N., Moalla, W., Attene, G., ... \& Chamari, K. (2013). The acute effect of whole body vibration on repeated shuttle-running in young soccer players. International journal of sports medicine, 35(1), 49-54. https://doi.org/10.1055/s-0033-1345171

Perchthaler, D., Hauser, S., Heitkamp, H. C., Hein, T., \& Grau, S. (2015). Acute effects of whole-body vibration on trunk and neck muscle activity in consideration of different vibration loads. Journal of sports science \& medicine, 14(1), 155 .

Rittweger, J., Beller, G., \& Felsenberg, D. (2000). Acute physiological effects of exhaustive whole-body vibration exercise in man. Clinical physiology, 20(2), 134-142. https://doi.org/10.1046/j.1365-2281.2000.00238.x

Ritzmann, R., Gollhofer, A., \& Kramer, A. (2013). The influence of vibration type, frequency, body position and additional load on the neuromuscular activity during whole body vibration. European journal of applied physiology, 113(1), 1-11. https://doi.org/10.1007/s00421-012-2402-0

Ritzmann, R., Kramer, A., Gruber, M., Gollhofer, A., \& Taube, W. (2010). EMG activity during whole body vibration: motion artifacts or stretch reflexes?. European journal of applied physiology, 110(1), 143-151. https://doi.org/10.1007/s00421-010-1483-x

Roelants, M., Verschueren, S. M., Delecluse, C., Levin, O., \& Stijnen, V. (2006). Whole-body-vibration-induced increase in leg muscle activity during different squat exercises. Journal of Strength and Conditioning Research, 20(1), 124.

Roll, J. P., Vedel, J. P., \& Ribot, E. (1989). Alteration of proprioceptive messages induced by tendon vibration in man: a microneurographic study. Experimental brain research, 76(1), 213-222. https://doi.org/10.1007/BF00253639

Romaiguère, P., Vedel, J. P., \& Pagni, S. (1993). Effects of tonic vibration reflex on motor unit recruitment in human wrist extensor muscles. Brain research, 602(1), 32-40. https://doi.org/10.1016/0006-8993(93)90237-H

Rønnestad, B. R. (2009). Acute effects of various whole-body vibration frequencies on lower-body power in trained and 
untrained subjects. The Journal of Strength \& Conditioning Research, 23(4), 1309-1315. https://doi.org/10.1519/JSC.0b013e318199d720

Rønnestad, B. R., Slettaløkken, G., \& Ellefsen, S. (2016). Adding whole body vibration to preconditioning exercise increases subsequent on-ice sprint performance in ice-hockey players. The Journal of Strength \& Conditioning Research, 30(4), 1021-1026. https://doi.org/10.1519/JSC.0b013e3182a9535a

Sands, W. A., McNeal, J. R., Stone, M. H., Kimmel, W. L., Gregory Haff, G., \& Jemni, M. (2008). The effect of vibration on active and passive range of motion in elite female synchronized swimmers. European Journal of Sport Science, 8(4), 217-223. https://doi.org/10.1080/17461390802116682

Torvinen, S., Kannus, P., SievÄnen, H., Järvinen, T. A., Pasanen, M., Kontulainen, S., ... \& Vuori, I. (2002). Effect of four-month vertical whole body vibration on performance and balance. Medicine \& Science in Sports \& Exercise, 34(9), 1523-1528. https://doi.org/10.1097/00005768-200209000-00020

Torvinen, S., Kannus, P., Sievänen, H., Järvinen, T. A., Pasanen, M., Kontulainen, S., ... \& Vuori, I. (2003). Effect of 8month vertical whole body vibration on bone, muscle performance, and body balance: a randomized controlled study. Journal of bone and mineral research, 18(5), 876-884. https://doi.org/10.1359/jbmr.2003.18.5.876

Verschueren, S. (2004a). Effects of 24 weeks of whole body vibration training on body composition and muscle strength in untrained females. Int. J. Sports Med., 25, 1-5. Roelants M, Delecluse C and Verschueren SM. Whole-body-vibration training increases knee-extension strength and speed of movement in older women. J Am Geriatr Soc. 2004; 52 (6): 901-908. https://doi.org/10.1111/j.1532-5415.2004.52256.x

Verschueren, S. M., Roelants, M., Delecluse, C., Swinnen, S., Vanderschueren, D., \& Boonen, S. (2004b). Effect of 6month whole body vibration training on hip density, muscle strength, and postural control in postmenopausal women: a randomized controlled pilot study. Journal of bone and mineral research, 19(3), 352-359. https://doi.org/10.1359/JBMR.0301245

\section{Copyrights}

Copyright for this article is retained by the author(s), with first publication rights granted to the journal.

This is an open-access article distributed under the terms and conditions of the Creative Commons Attribution license which permits unrestricted use, distribution, and reproduction in any medium, provided the original work is properly cited. 